Article

\title{
Influence of Laboratory Compaction Method on Compaction and Strength Characteristics of Unbound and Cement-Bound Mixtures
}

\author{
Matija Zvonarić * (D), Ivana Barišić (D), Mario Galić (D) and Krunoslav Minažek \\ Faculty of Civil Engineering and Architecture Osijek, Josip Juraj Strossmayer University of Osijek, \\ Vladimira Preloga 3, 31000 Osijek, Croatia; ivana@gfos.hr (I.B.); mgalic@gfos.hr (M.G.); krumin@gfos.hr (K.M.) \\ * Correspondence: mzvonaric@gfos.hr
}

check for

updates

Citation: Zvonarić, M.; Barišić, I.; Galić, M.; Minažek, K. Influence of Laboratory Compaction Method on Compaction and Strength

Characteristics of Unbound and Cement-Bound Mixtures. Appl. Sci. 2021, 11, 4750. https://doi.org/ 10.3390/app11114750

Academic Editor: Malgorzata Jastrzebska

Received: 12 April 2021

Accepted: 17 May 2021

Published: 21 May 2021

Publisher's Note: MDPI stays neutral with regard to jurisdictional claims in published maps and institutional affiliations.

Copyright: (C) 2021 by the authors. Licensee MDPI, Basel, Switzerland. This article is an open access article distributed under the terms and conditions of the Creative Commons Attribution (CC BY) license (https:/ / creativecommons.org/licenses/by/ $4.0 /)$.

\begin{abstract}
During road construction, granular materials for the unbound base course (UBC) and cement-bound base course (CBC) are mostly compacted by vibratory rollers. A widespread laboratory test for determining the optimal moisture content (OMC) and maximum dry density (MDD) of the mixture for installation in UBC and CBC is the Proctor test. Considering that the Proctor test does not produce any vibrations during compaction, this paper compares the Proctor test and the vibrating hammer test. The examination was conducted on UBC and CBC with varying cement content and aggregate types. All mixtures were compacted by both methods with the aim of determining the compaction and strength characteristics. The results indicated the high comparability of the two test methods for mixtures with natural aggregate in terms of MDD, OMC, density and strength characteristics (California bearing ratio (CBR) for UBC and 28-day compressive strength for $\mathrm{CBC}$ ). For mixtures with higher cement content, the OMC difference depending on the laboratory compaction method used can be significant, so the laboratory compaction method should be chosen carefully, particularly for moisture-susceptible materials. This paper also reveals that by increasing the proportion of rubber in the mixture, the compaction and strength characteristics differ significantly due to the compaction method. Therefore, when using alternative and insufficiently researched materials, the compaction method should also be chosen carefully.
\end{abstract}

Keywords: cement bound base course; unbound base course; compaction technology; Proctor test; vibrating hammer test; recycled rubber

\section{Introduction}

Compaction is a significant process in pavement construction. For pavement installation, all the installed layers must be compacted to the target degree of compaction and density. As a result of the application of the required compaction effort, a certain targeted porosity and shear strength of the compacted material is achieved. Also, compaction has a great impact on the pavement load-bearing capacity. Good compaction is a guarantee of the road service level [1]. The compaction of pavement courses is performed by various types of roller or plate compactors [2] and the selection of the type of compaction machine has a significant impact on the compaction characteristics achieved. An overview of the importance and historical development of road compaction technology is presented in [3]. Commonly for road construction, several different types of roller are used, i.e., smoothwheel rollers, pneumatic rollers, and sheepsfoot rollers. Their dead weight, drum width, and diameter are common characteristics for all rollers, but all rollers differ in certain properties. Smooth-wheel rollers appear as static, vibratory, and oscillating. Static rollers can consist of one, two, or three drums and they rely on dead weight, speed and the number of passes. On the other hand, the vibratory rollers' efficiency greatly depends on their weight, speed, amplitude, and the frequency of the drum. Namely, a drum consists of one or two eccentric and rotating masses that produce vibrations. By compacting with vibratory rollers, 
the friction of the material during compaction reduces, and aggregate grains nest more easily into the cavities in the mixture. Dynamic compaction gives the best effect in compacting cohesionless materials [4-7]. Fathi et al. [8] tried to examine the depth of influence of intelligent compaction rollers using simulated and field data. Research has shown an increasing depth of influence for granular materials, while the influence decreases with increase in the cohesion of the compacted material. In road construction, large areas have to be uniformly compacted to the targeted degree of compaction and density. Taking into account the aforementioned, the simultaneous control of all the parameters for effective compaction tends to be a challenging task. Nowadays the continuous compaction control method (CCC), presented in more detail in [9], is widespread. CCC allows control of the compaction effect achieved in real time, based on the dynamic response of the interaction between the drum and the layer being installed $[10,11]$. Most recently, published studies are presenting the developing approach of quality control and acceptance (QC/QA) based on intelligent compaction (IC) technology in road construction, which is arguably dependent on and determined by the development of sensor technology and robotic operations [3,12-14]. In [1], the main drawbacks of existing compaction assessment methods are underlined, based on discrete manual measurements, such as the inability to provide results on the quality of the compaction of the entire road, as well as being potentially destructive of the layers and time-consuming. The authors presented a QC/QA-based IC technology with an alternative measurement based on a changing pattern of compaction meter values $(\mathrm{CMV})$ in regard to the number of compaction roller passes. They reported that this is more likely to achieve the desired compaction quality under the optimal moisture content (OMC) situation. A similar approach is presented in [15], comprising the implementation of roller-integrated CCC technology on granite residual subgrades. The authors underlined in their conclusions that the roller operation parameters and lift thickness should be kept constant during further quality assurance using the roller-integrated CCC technology, since the roller measurement values rely strongly on the roller operation parameters and lift thickness, especially for cement-treated layers. As for further research, the authors suggest investigating the effect of the moisture content on the roller measurement values, as well as the correlations between the roller measurement values and further location-specific in situ point measurements. The results of a geostatistical analysis of IC technology showed that this technology can provide detailed information about the uniformity of the spatial compaction and that it could be adopted to monitor the changes in spatial uniformity during the compaction [16].

Finally, for effective compaction, appropriate material needs to be used, with proper aggregate gradation and binder content depending on the constructed bearing layer. The recipe for the reference mixture is obtained by laboratory testing. For a proper reference mixture definition in laboratory conditions, realistic on-site conditions need to be simulated through proper simulation of the in-situ compaction energy and other conditions. The standard laboratory tests for determining the maximum dry density (MDD) and OMC are the Proctor test, vibrating hammer, and vibrating table [17,18].

The unbound base layer is an indispensable part of every pavement, made of a mixture of unbound granular stone materials. The main characteristics of this layer are the degree of compaction and the modulus of compressibility. In pavements with a heavy traffic load, a hydraulically bound base layer is installed on the unbound base layer, which is a mixture of well-graded aggregate, hydraulic binder and an appropriate amount of water. The main feature of this layer is the degree of compaction and compressive strength. To determine the compaction parameters in laboratory conditions, the most widespread test is the Proctor test, while other test methods can also be applied. Since granular soils are mostly compacted by vibrating rollers, with vibration compaction, it can be inferred that the Proctor test does not give sufficiently realistic results, because it does not use any vibrations during specimen compaction. As an alternative to sample preparation by the Proctor compaction method, vibratory hammer compaction can be used. Izaquiredo et al. [19] concluded that when using the Proctor compaction method, grains tend to pre-shred and be unevenly 
distributed, which leads to unrealistically high optimal moisture content and maximum dry density values which are hard to achieve in real compaction. Sengün et al. [18] compared four compaction methods on roller-compacted concrete mixtures to determine the compressive strength. The results proved the better efficiency of the vibrating hammer test than the modified Proctor test for mixtures that contain lower amounts of cement, while for mixtures with higher cement content, smaller differences between the test methods are observed. Also, Drnevich and Evans [20] claim that the vibrating hammer represents the field compaction conditions of granular soils better than the vibrating table test. Hoff et al. [21] studied the influence of different laboratory compaction methods on the resistance to permanent deformation of unbound granular materials. Comparisons were made for samples compacted with four different methods: gyratory compactor, modified Proctor, vibratory table and vibratory hammer, and showed that the modified Proctor method shows less resistance to permanent deformation than methods based on vibration. McLachlan and Bagshaw [22] addressed the standardization of laboratory compaction energies for different compaction methods, giving the description and comparison of three compaction methods; vibratory hammer, vibrating table and gyratory compactor, considering, among other parameters, costs, ease of use, consistent energy input as well as correlation with field compaction. As the alternative methods were weighted on the vibrating hammer test till such a decision is made, the recommendation on the vibrating hammer standard should be revised and made more precise, e.g., requiring calibration. Investigations of the effects of different laboratory compaction methods on the properties of cement-stabilized materials were done by $\mathrm{Wu}$ and Houben [23]. The mechanical performance of cement-stabilized samples of three types of soil—sand, sandy clay and clay—were compared, defining the appropriate technique for compaction of each of the soil types used. It was observed that for sand materials vibratory compaction gives substantially higher densities compared to the Proctor test (resulting in two times higher compressive and indirect tensile strength), and also that there is an increase in densities for stabilized sandy clay, as opposed to clay and stabilized clay, where no obvious improvement is noticed. A new soil compaction vibratory machine which can produce densities and optimal moisture contents that would mimic the Proctor test is described in [17], with the conclusion that soil densities increased with the increasing amplitude, time, and frequency of the machine, and that the vibratory soil compactor would work best at a frequency of $17 \mathrm{~Hz}$ and amplitude of $1.17 \mathrm{~mm}$ for $5 \mathrm{~min}$. Field test results presented in [24] on the energy transferred to the ground compacted by a 4-sided impact roller confirmed that the towing speed influences the pressure imparted to the ground and hence the compaction effort, and that the current practice of using either kinetic energy or gravitational potential energy should be avoided, as neither can accurately quantify the rolling dynamic compaction when the towing speed is varied.

This research aimed to determine the applicability of the vibrating hammer method compared to the modified Proctor test in the testing of unbound and hydraulically bound mixtures for pavement purposes using standard and some non-standard materials (waste rubber). The main purpose of the research conducted was to compare the compaction test conditions and their influence on the material behaviour through compaction and strength characterization. Also, the appropriateness of the two compaction methods on an alternative, waste material - waste rubber - was investigated. Namely, the use of waste rubber in the cement-bound base course $(\mathrm{CBC})$ can reduce the occurrence of reflective cracks in the asphalt wearing course, resulting in natural resource preservation and extended service life of a pavement structure $[25,26]$. Little research has been done on effect of crumb rubber on cement bound mixtures, while extensive research has been conducted on rubberized concrete. Natural aggregate replacement by crumb rubber inevitably contributes to the reduction of compressive strength, for which some researches have established a prediction model [27]. Crumb rubber addition to concrete changes failure pattern from brittle to ductile at the microscale observation and shows better performance under severe dynamic loads at the macroscale observation [28]. According to [29] rubber addition in concrete improves its resistance to frost which, besides brittleness, is a major problem in 
$\mathrm{CBC}$ mixtures. Encouraged by positive impact of rubber on concrete, authors decide to examine the influence of crumb rubber on $\mathrm{CBC}$. Due to their long decomposition time, waste tyres cause severe environmental issue. This problem is growing every day, as the number of vehicles on roads increase all over the world. Therefore, application of waste tyres in engineering structures, especially the big one as road infrastructure may have a great impact on environment.

\section{Materials and Methods}

Within this research, for the unbound bearing course and cement-bound course, natural aggregates (sand and gravel) with different gradations (i.e., $0-2 \mathrm{~mm}, 0-4 \mathrm{~mm}$, 4-8 $\mathrm{mm}$, and $8-16 \mathrm{~mm}$ ) were used (Figure 1). Due to its similar grain size distribution, as an alternative to the $0-2 \mathrm{~mm}$ fraction, a fine fraction of recycled rubber was used (Figure 2). The chosen material was prepared according to EN 933-1 [30] with a grain size distribution curve to fit between the upper and lower limits according to EN 13285 [31] for the unbound base course (UBC) material (mixture named 0\%C), and EN 14227-1 [32] for the cementbound material (CBC). For CBC, Portland cement of grade 32.5 (CEM II B/M (P-S) 32.5R) was used as a binder, comprising $3 \%, 5 \%$, and $7 \%$ of the total aggregate mass. Solid particle densities were determined in a pycnometer according to standard EN 1097-6 [33]. The density of the $0-2,0-4,4-8$, and $8-16 \mathrm{~mm}$ natural aggregate fractions used was 2.86 , $2.96,2.63$ and $2.70 \mathrm{~g} / \mathrm{cm}^{3}$ respectively, while the waste rubber density of $1.12 \mathrm{~g} / \mathrm{cm}^{3}$ was determined using ethanol instead of water due to its low density (similar to water). The density of the cement used was $2.92 \mathrm{~g} / \mathrm{cm}^{3}$, determined by standard EN 196-6 [34]. Three additional mixtures for the $\mathrm{CBC}$ were designed, within which the binder content of $5 \%$ was selected as an optimal share according to previous research using the same aggregate type [35] in order to preliminarily determine the influence of the waste rubber on the CBC mixture characteristics. In those mixtures, the $0-2 \mathrm{~mm}$ fraction was replaced with granular rubber (due to a similar grain size distribution) by volumetric percent (due to high-density differences between these two materials). The replacement was in amounts of $20 \%$ (mixture $5 \% \mathrm{C}+20 \% \mathrm{R}$ ), $30 \%$ (mixture $5 \% \mathrm{C}+30 \% \mathrm{R}$ ) and $60 \%$ (mixture $5 \% \mathrm{C}+60 \% \mathrm{R}$ ) of the $0-2 \mathrm{~mm}$ fraction volume in the mix. When recalculated, the $0-2 \mathrm{~mm}$ fraction replacement by rubber in amounts of $20 \%, 30 \%$ and $60 \%$ represents $4.64 \%, 6.95 \%$ and $13.91 \%$ of the total aggregate volume of the mixture respectively, and $1.92 \%, 2.93 \%$ and $6.13 \%$ of the total aggregate mass of the mixture. Table 1 presents the proportions of all the constituents in the mixtures.

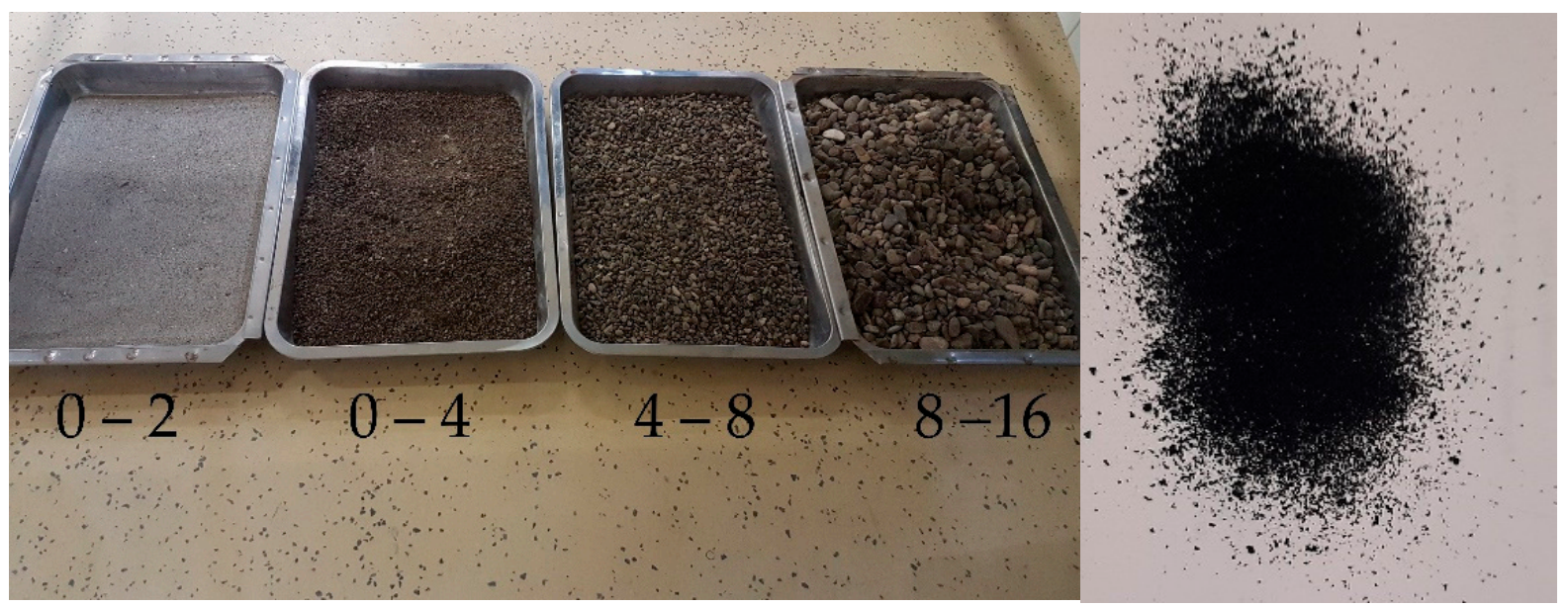

Figure 1. Natural aggregate and waste rubber used. 


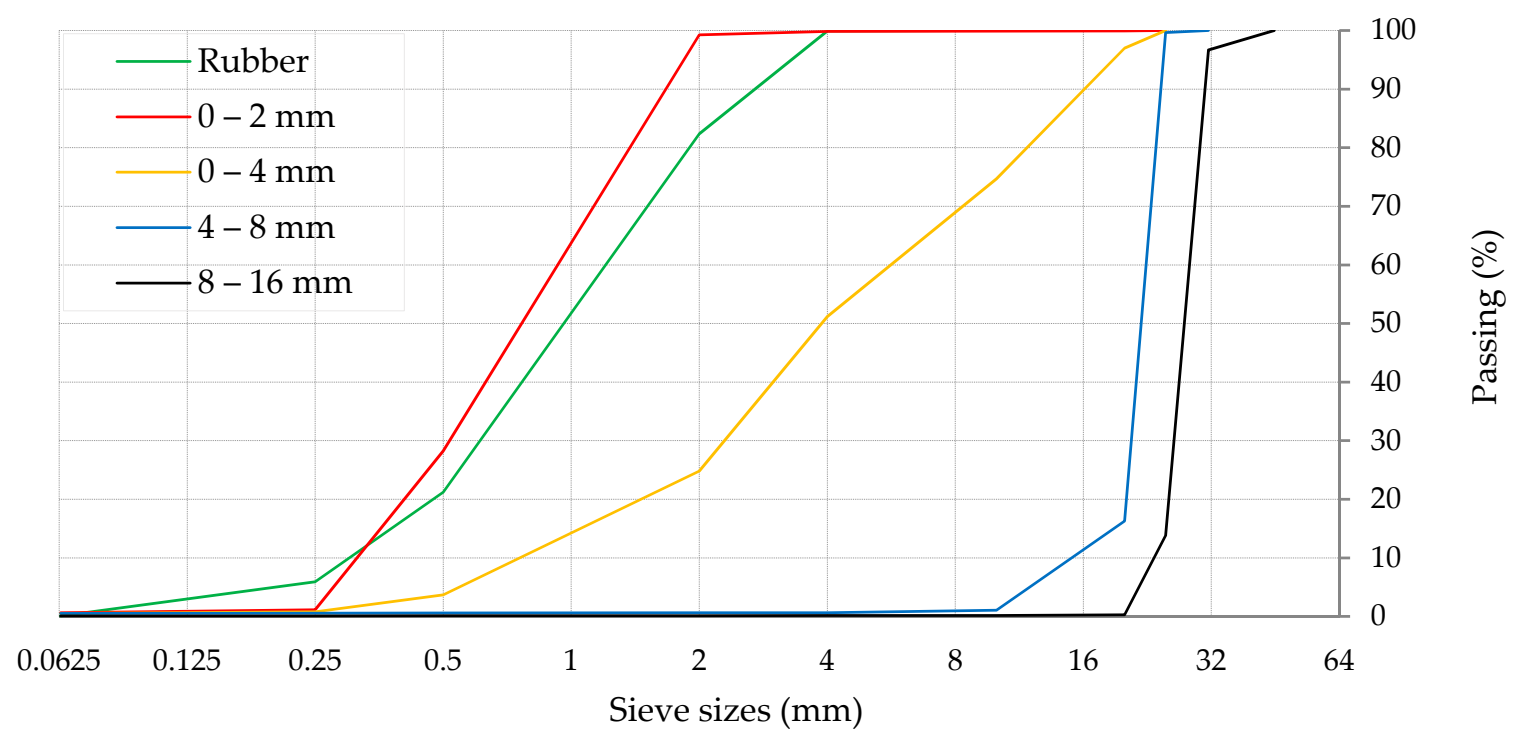

Figure 2. Grain size distribution curve of materials used.

Table 1. Unbound base course (UBC) and cement-bound base course (CBC) mixture compositions.

\begin{tabular}{|c|c|c|c|c|c|c|c|}
\hline Mix & $0 \% \mathrm{C}$ & $3 \% \mathrm{C}$ & $5 \% C$ & $7 \% \mathrm{C}$ & $5 \% C+20 \% R$ & $5 \% C+30 \% R$ & $5 \% \mathrm{C}+60 \% \mathrm{R}$ \\
\hline Cement [vol.\%] & 0 & 2.78 & 4.56 & 6.26 & 4.56 & 4.56 & 4.56 \\
\hline 0-2 mm [vol.\%] & 19.60 & 23.61 & 23.18 & 22.77 & 18.54 & 16.23 & 9.27 \\
\hline 0-4 mm [vol.\%] & 38.00 & 22.87 & 22.46 & 22.06 & 22.46 & 22.46 & 22.46 \\
\hline 4-8 mm [vol.\%] & 32.00 & 25.69 & 25.21 & 24.76 & 25.21 & 25.21 & 25.21 \\
\hline 8-16 mm [vol.\%] & 10.40 & 25.05 & 24.59 & 24.15 & 24.59 & 24.59 & 24.59 \\
\hline Rubber [vol.\%] & 0 & 0 & 0 & 0 & 4.64 & 6.95 & 13.91 \\
\hline Mix volume [\%] & 100 & 100 & 100 & 100 & 100 & 100 & 100 \\
\hline
\end{tabular}

In order to compare the results from the Proctor and vibrating hammer tests, the tests were conducted on both the unbound base course mixture and cement-bound base course mixture. The modified Proctor test was done using an automatic Proctor compaction machine and the operator (human) factor on compaction is minimized. On the other hand, as described in standard EN 13286-51 [36], the vibrating hammer is greatly affected by human influence.

To find the OMC and MDD, five test specimens with five different amounts of water were prepared for each test method and each tested mixture, following the recommendations of EN 13286-2 and 13286-4 [37,38]. Both test methods require the use of the Proctor mould B (150 mm diameter and $120 \mathrm{~mm}$ height) for the chosen aggregate mixture, which makes the test results comparable (Figure 3). Specimen preparation using the Proctor hammer consisted of specimen compaction in 5 layers, with 56 blows per layer with a $4.5 \mathrm{~kg}$ rammer falling from $457 \mathrm{~mm}$ height, which is equal to a modified Proctor energy of $2.66 \mathrm{MJ} / \mathrm{m}^{3}$. The amount of material, placed in each of 5 layers, must occupy one fifth $(1 / 5)$ of the mould after layer compaction. For specimen preparation using the vibrating hammer, standard [38] prescribes the compaction of a specimen in 3 layers with $60 \mathrm{~s}$ of vibration per layer. Analogous to the previously explained method, the amount of the material, placed in each of 3 layers, must occupy one third (1/3) of the mould after compaction of the layer. A vibrating hammer with a weight of $6.4 \mathrm{~kg}$ and power of $1100 \mathrm{~W}$ is placed on a supporting frame and has a $146 \mathrm{~mm}$ diameter tamping foot as an extension. To prevent the hammer bouncing, a surcharge load during compaction was entered by an operator, whereby the total weight of the hammer with the additional load was between 300 and 400 N. Prior 
to the start of the test, the operator used a balance to determine how much pressure on the hammer corresponds to a force input of approximately $300 \mathrm{~N}$ so that the applied force with the hammer weight seemed a force between $300 \mathrm{~N}$ and $400 \mathrm{~N}$. Operator experience is required to estimate the appropriate amount of material for each layer. Considering that the duration of specimen compaction by the Proctor hammer was longer than the cement's initial setting time, the mixtures prepared for compaction by the vibrating hammer were left to cure for 10-15 min in order to enable cement hydration. Calculation of the OMC and MDD for both methods used was undertaken following the specifications given in standards EN 13286-2 [37] and 13286-4 [38].

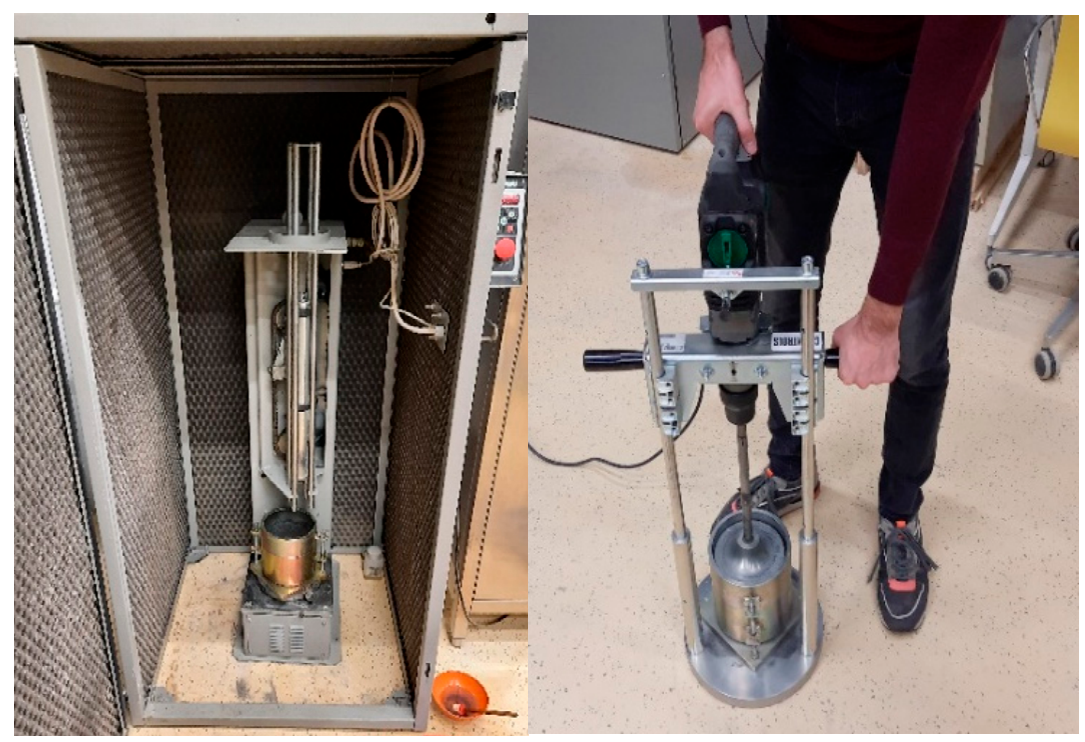

(a)

(b)

Figure 3. (a) Specimen preparation by Proctor method; (b) specimen preparation by vibrating hammer (operator entering surcharge during compaction).

For mechanical characterization, the California bearing ratio (CBR) test and compressive strength test were conducted according to the standards EN 13286-47 [39] and EN 13286-41 [40] respectively. CBR is used to characterize the bearing capacity of UBC after 4 days under a full soaking curing regime and with $2 \mathrm{~kg}$ surcharge discs. The compressive strength determined as a stress at failure of a specimen under uniaxial unconfined compression is used to characterize the bearing capacity of CBC. Both tests were conducted on samples made at their OMC according to both methods, the Proctor compaction [41] and vibrating hammer [36]. For compressive strength and CBR determination, three test specimens for each mixture by both methods were prepared in order to establish the validity of the research. Average values of the obtained results are presented as the relevant value for each mechanical characteristic. The presented average value is calculated between results which vary less than 20\% according to the propositions of EN 14227-1 [32].

For CBC mixtures, density $\rho$ as a ratio of the mass to the volume of the sample after a 28-day curing period is calculated in order to analyse the effectiveness of the compaction methods.

\section{Results and Discussion}

On samples prepared using both (Proctor compaction and vibrating hammer) methods, mechanical characteristics were determined and Table 2 presents the average results for three samples. 
Table 2. Results obtained by two test methods, vibrating hammer (marked green) method and Proctor (marked red), respectively.

\begin{tabular}{|c|c|c|c|c|c|c|c|}
\hline & $0 \% \mathrm{C}$ & $3 \% \mathrm{C}$ & $5 \% \mathrm{C}$ & $7 \% \mathrm{C}$ & $5 \% \mathrm{C}+20 \% \mathrm{R}$ & $5 \% \mathrm{C}+30 \% \mathrm{R}$ & $5 \% \mathrm{C}+60 \% \mathrm{R}$ \\
\hline OMC [\%] & $4.79 / 4.72$ & $4.91 / 5.15$ & $5.35 / 5.87$ & $5.53 / 6.10$ & $5.32 / 5.53$ & $5.21 / 5.13$ & $4.94 / 4.94$ \\
\hline $\operatorname{MDD}\left[\mathrm{g} / \mathrm{cm}^{3}\right]$ & $2.01 / 1.97$ & $2.08 / 2.09$ & $2.12 / 2.12$ & $2.15 / 2.15$ & $2.10 / 2.06$ & $2.03 / 2.03$ & $1.87 / 1.89$ \\
\hline$\rho\left[\mathrm{g} / \mathrm{cm}^{3}\right]$ & $\begin{array}{c}\text { not } \\
\text { applicable }\end{array}$ & $2.17 / 2.28$ & $2.21 / 2.29$ & $1.96 / 2.37$ & $2.18 / 2.23$ & $2.07 / 2.18$ & $1.96 / 2.05$ \\
\hline CBR [\%] & $101 / 98$ & $\begin{array}{c}\text { not } \\
\text { applicable }\end{array}$ & $\begin{array}{c}\text { not } \\
\text { applicable }\end{array}$ & $\begin{array}{c}\text { not } \\
\text { applicable }\end{array}$ & $\begin{array}{c}\text { not } \\
\text { applicable }\end{array}$ & $\begin{array}{c}\text { not } \\
\text { applicable }\end{array}$ & $\begin{array}{c}\text { not } \\
\text { applicable }\end{array}$ \\
\hline $\mathrm{f}_{\mathrm{c}}[\mathrm{MPa}]$ & $\begin{array}{c}\text { not } \\
\text { applicable }\end{array}$ & $4.11 / 4.06$ & $7.59 / 7.60$ & $12.99 / 12.92$ & $1.89 / 3.13$ & $1.33 / 2.48$ & $0.49 / 0.94$ \\
\hline
\end{tabular}

\subsection{Compaction Characteristics}

The results of the tests conducted are presented in Table 2 and Figure 4. For mixtures with natural aggregate $(0 \% \mathrm{C}, 3 \% \mathrm{C}, 5 \% \mathrm{C}, 7 \% \mathrm{C})$, similar results are obtained with both compaction methods. The difference between the MDD values obtained is less than those of OMC. For cement-bound mixtures, similar MDD values (third decimal difference) are obtained, but Proctor compaction required a higher water content. Generally, the vibrating hammer compaction method provides a lower OMC for the same MDD values. The similarity of the results obtained leads to the conclusion of the high comparability of the two test methods for mixtures with natural aggregate. It can be concluded that the vibrating hammer compaction method can be used as an alternative to the modified Proctor compaction method since it is more practical and less time-consuming. A similar observation is presented in [20], where the authors also state that, compared with the standard Proctor method, higher OMC and MDD values should be expected when using the vibrating hammer compaction method.

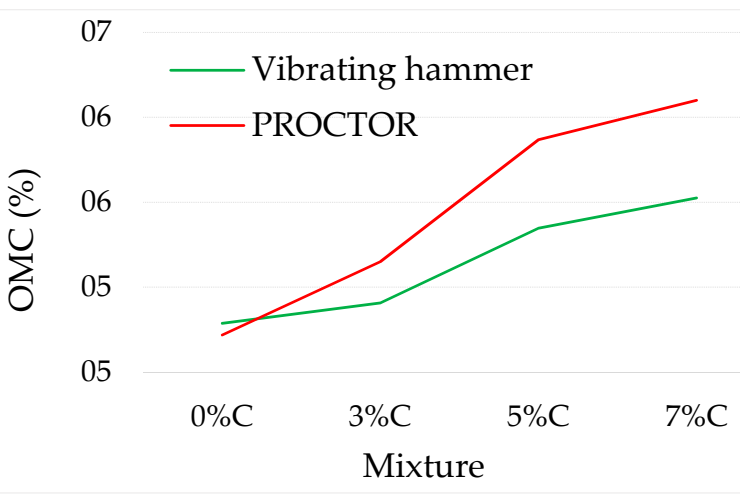

(a)

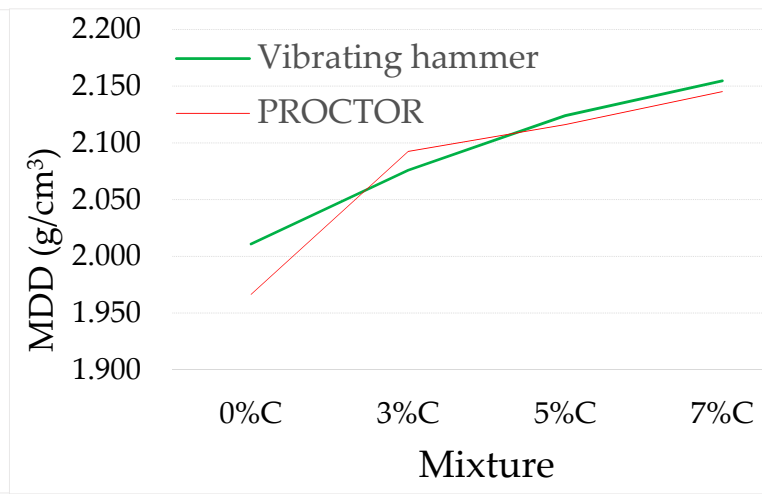

(b)

Figure 4. (a) Optimal moisture content (OMC) and (b) maximum dry density (MDD) for UBC and CBC mixtures.

Also, an expected increase in OMC and MDD is observed with the increase in cement content for both the compaction methods used. The cement hydration reaction and cement paste creation require more water for a higher cement content within the mixture [42]. The vibrating hammer is a less time-consuming method, considering compaction in 3 layers for $60 \mathrm{~s}$ per layer and time taken for filling the mould with material, gives about $5 \mathrm{~min}$ per specimen. So the lower OMC could be the result of less time being available for the cement's initial setting time and less water being used for initial hydration. To be more precise, cement has more time available for hydration in the Proctor compaction method. Unlike the $60 \mathrm{~s}$ for the vibrating hammer method, 56 blows per layer take longer. With a longer compaction of the one layer, the Proctor method still requires a larger number of layers (5), which makes this process longer still and takes approximately $15 \mathrm{~min}$ per 
sample. From this discussion, it can be concluded that the specimen compacted by the Proctor method has about 3 times more time for cement hydration which requires more water, compared to vibrating hammer specimens. However, similar strength characteristics are obtained and high comparability is observed. For higher cement content mixtures, the OMC difference depending on the laboratory compaction method used can reach $0.6 \%$, so the laboratory compaction method should be chosen carefully, particularly if moisture-susceptible materials are used.

As expected, the addition of waste rubber results in a decrease in both the OMC and MDD values compared to the natural aggregate mixture with the same binder content. This is a result of rubber's hydrophobic nature, rough surface (Figure 5), and low density, but also its high elasticity that absorbs some of the compaction energy. As can be seen from Figure 5, rubber particles have more irregular and indented surface which captures air molecules thus taking up more space in the structure of the mixture which reduce the volume of the mixture that hydrates with cement. Furthermore, for irregularly shaped particles it is more difficult to adhere to the particles with flat surfaces, such as sand particles, and thus create larger gaps in the mixture. The results are in accordance with some previous research dealing with waste rubber applications in the pavement system [26,43,44]. From Table 2, it can be noted that there is a larger difference in OMC than MDD between waste rubber and non-waste rubber mixtures for the Proctor compaction method. This greater drop in the compaction characteristics for the Proctor compaction method means that the choice of laboratory compaction method should be made carefully if alternative materials are used.

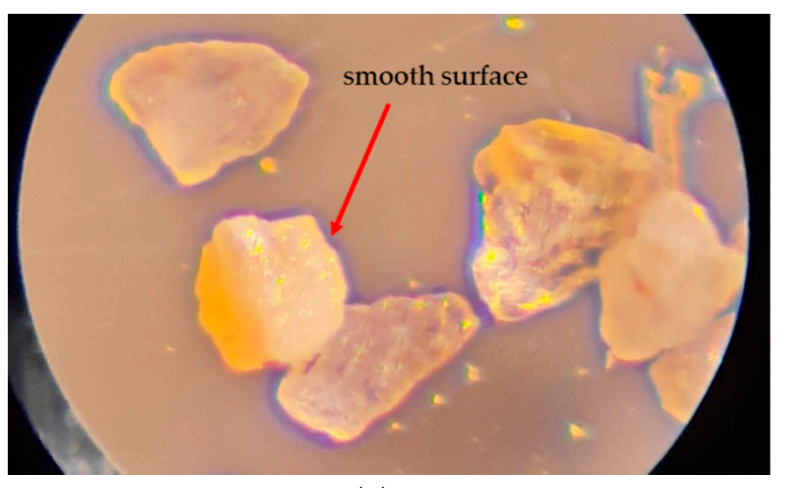

(a)

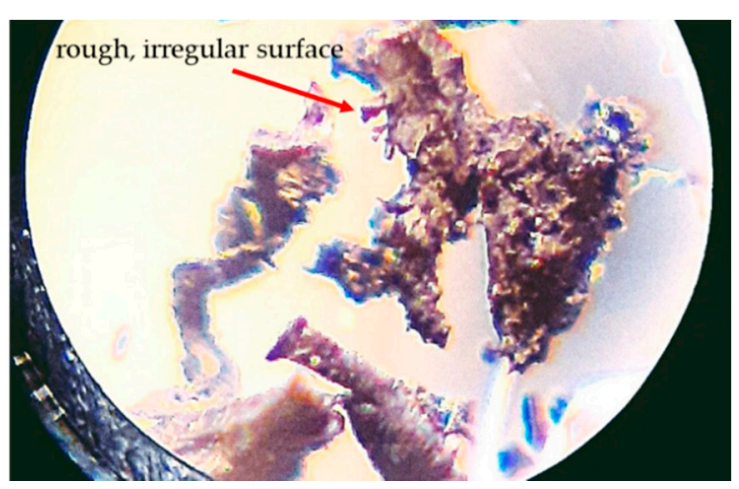

(b)

Figure 5. Optical microscopy image of sand grain (a) and waste rubber grain (b).

As presented in Table 2, a lower density $(\rho)$ is observed for the vibrating hammer method compared to the modified Proctor compaction method, for which an increasing trend is observed with an increase of the cement content. However, for the vibrating hammer method, with a high cement content a decrease in density occurred. During compaction, a cement paste layer formed on the sample surface at the end of each compaction layer (Figure 6), resulting in a decrease of the apparent density. Under high vibrations and a high cement paste content within the mixture, segregation occurred, influencing the apparent density decrease. The same phenomenon can explain the high compressive strength difference for higher values of $f_{c, 28}$. Namely, cement paste segregation on the sample surface caused uneven density of the sample and a higher $\mathrm{f}_{\mathrm{c}, 28}$ difference when comparing the two compaction methods, as presented in Figure $7 \mathrm{~b}$. 

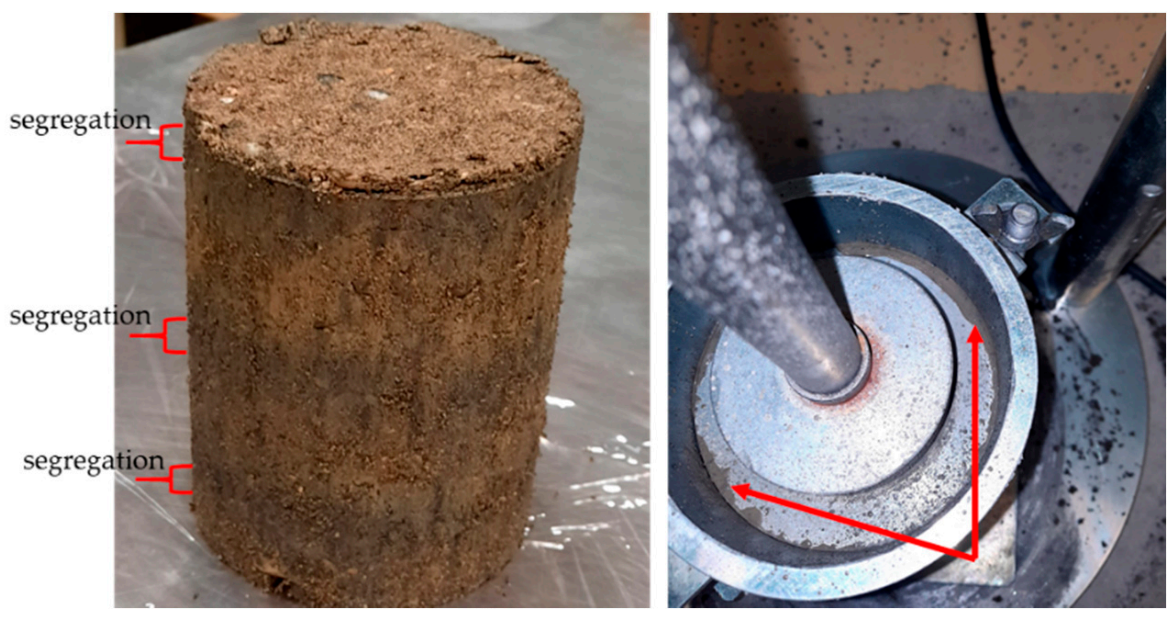

Figure 6. Vibrating hammer compaction of mixture with high cement content.

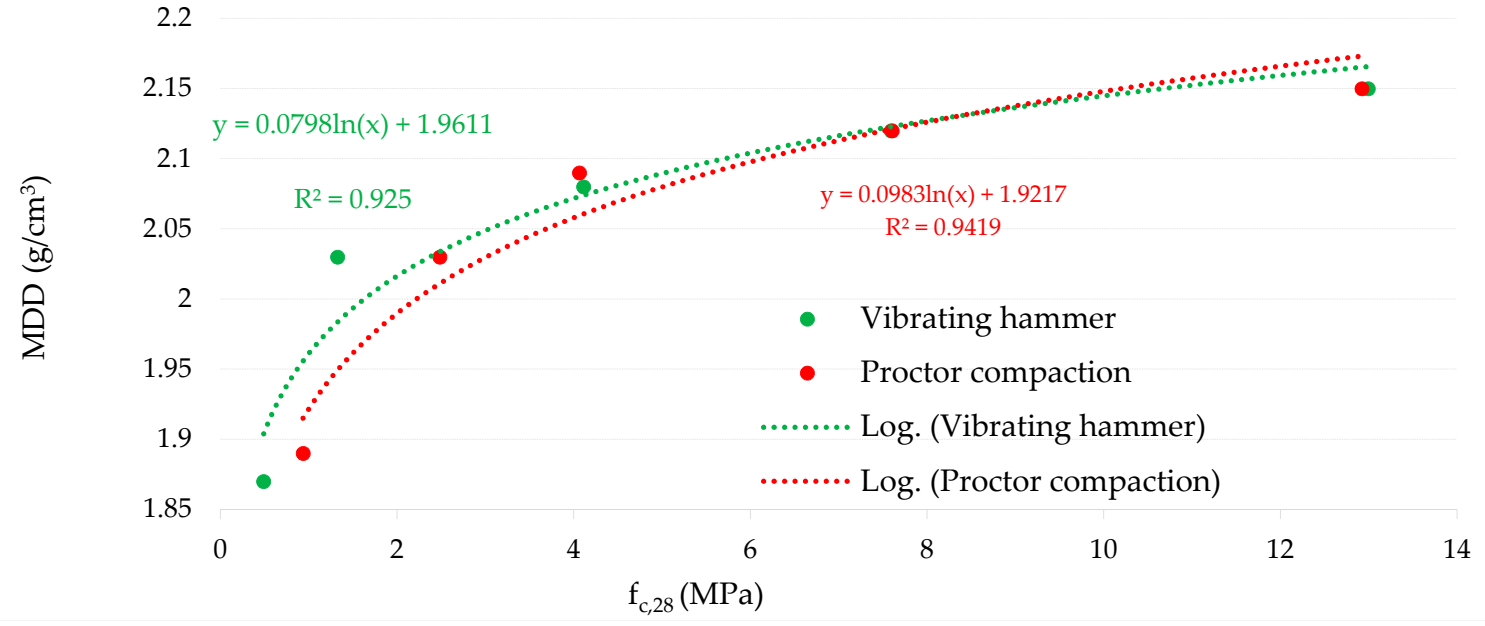

(a)

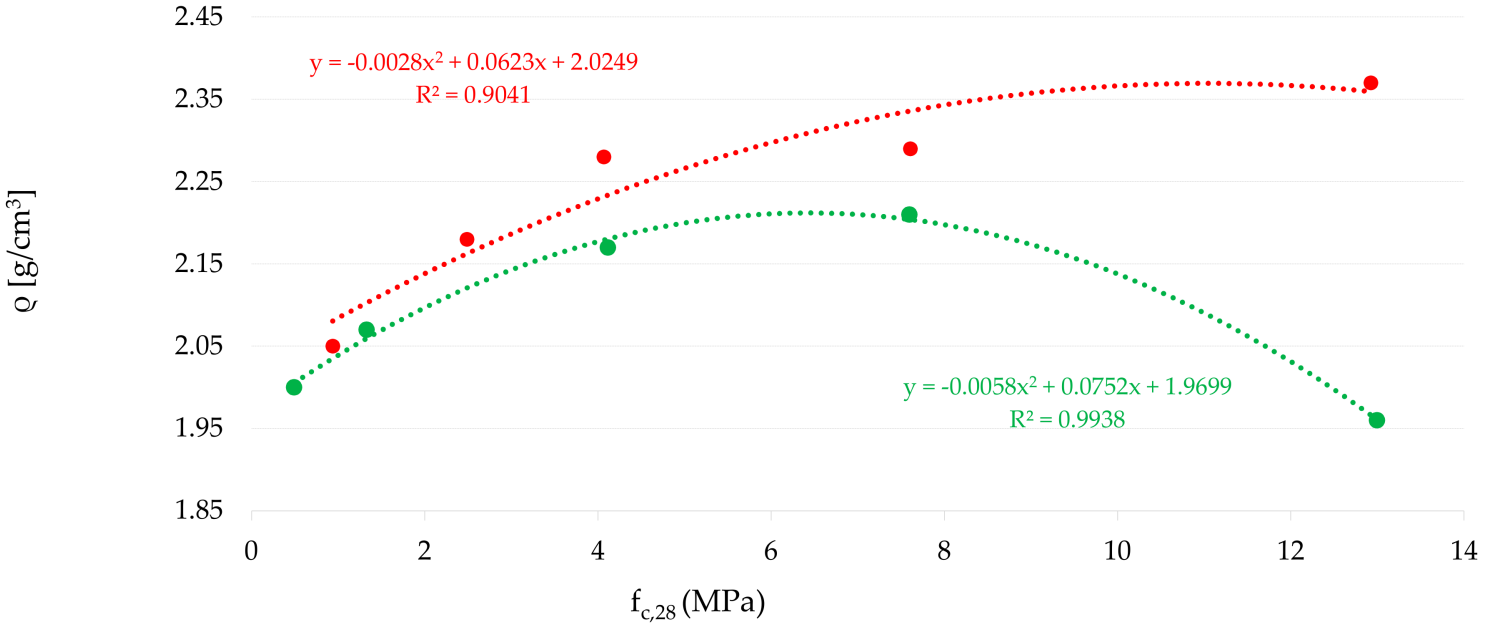

(b)

Figure 7. Correlation between compressive strength and MDD (a) and density (b).

The addition of waste rubber also resulted in a density decrease due to the lower rubber density compared to the replaced sand. The rubber's high elasticity and compaction energy absorption resulted in a greater difference in the measured density. For the vibrating 
hammer method a $1.63 \%, 6.3 \%$ and $11.31 \%$ decrease in density occurred for $20 \%, 30 \%$ and $60 \%$ sand replacement by rubber respectively, while for the Proctor compaction method the density reduction was $2.62 \%, 4.8 \%$ and $10.53 \%$ compared to the reference mixture $(5 \% \mathrm{C})$.

\subsection{Strength Characteristics}

Strength characterization of the UBC was undertaken by measuring the CBR. As presented in Table 2, similar results were obtained for both the compaction methods used. Therefore, again the high comparability of the test results can be observed, but, as indicated earlier, due to variation in the OMC, the compaction method for moisture-susceptible materials should be chosen carefully.

Strength characterization of CBC was undertaken by measuring the 28-day compressive strength and the results are presented in Table 2 and Figure 7 . Small differences can be observed between the two compaction methods for natural aggregate mixtures. As expected, an increase in $\mathrm{f}_{\mathrm{c}, 28}$ is observed for the cement content due to the formation of calcium silicate hydrates (C-S-H gel), which is mostly responsible for the development of compressive strength. A decrease in compressive strength is observed with the addition of waste rubber, which is in accordance with some previous research [44]. For mixtures with waste rubber, a higher compressive strength is recorded for the Proctor compaction method. The differences between the two compaction methods used are $39.62 \%, 46.4 \%$ and $47.9 \%$ for $20 \%, 30 \%$ and $60 \%$ sand replacement by rubber respectively. To analyse this high compressive strength difference between the two compaction methods used, the correlation of $\mathrm{f}_{\mathrm{c}, 28}$ and compaction characteristics (MDD and density) is presented in Figure 7.

There is a high correlation between the compressive strength and MDD regardless of the compaction method. Also, the same conclusion can be drawn for the correlation between $\mathrm{f}_{\mathrm{c}, 28}$ and $\rho$. Since the MDD and $\rho$ are influenced by the lower density of rubber, that is one reason for the lower $\mathrm{f}_{\mathrm{c}, 28}$ of rubber mixtures and the high difference between the compaction methods. However, for mixtures with waste rubber, the difference between MDD and $\rho$ is much smaller compared to the $f_{c, 28}$ difference obtained by the two compaction methods. The reason could be the great difference in the behaviour of the rubber mixtures when different compaction methods are used but also when the compression test is conducted. This finding presents a good basis for further research. Finally, the optimal waste rubber content is expected to be up to $30 \%$ sand replacement, since a higher rubber content could lead to a drop in the 28-day compressive strength under $2 \mathrm{MPa}$, as is usually required for most pavement purposes.

\section{Conclusions}

Within this paper, the compaction characteristics of unbound and cement-bound mixtures for application as a pavement base course are investigated on two aggregate types using two laboratory compaction methods. The purpose of these tests was to compare the efficiency and difference in the compaction and strength characteristics achieved in the well-known Proctor test and, less commonly used in practice, the vibrating hammer test. The conclusions presented are drawn from the research conducted on a limited number of samples and, to reach general conclusions, more tests are to be conducted. Based on the laboratory research results, several conclusions can be drawn:

- There is strong correlation between the compaction and strength characteristics obtained in laboratory conditions using the modified Proctor and vibrating hammer compaction methods for natural aggregate mixtures.

- A greater drop in the compaction characteristics for rubber mixtures and the use of the Proctor compaction method lead to the conclusion that the laboratory compaction method should be chosen carefully if alternative materials such as waste rubber are used.

- For higher cement content mixtures, a higher OMC difference depending on the laboratory compaction method used is observed and the laboratory compaction method should be chosen carefully, particularly if moisture-susceptible materials are used. 
- Comparing the compaction effects (MDD, OMC and density), it can be observed that approximately the same compaction energy was applied using both compaction methods. However, calculation of the compaction energy using a vibrating hammer is more difficult than for the Proctor test, and it should be investigated in more detail. Further research should provide an additional insight into the comparability of the vibrating hammer and standard Proctor tests, applying less compaction energy than the modified Proctor test used in this research.

- The choice of laboratory compaction method should be made carefully depending on the specific behaviour of materials used and the expected field conditions.

Author Contributions: Conceptualization, I.B. and M.Z.; methodology, I.B.; validation, I.B., M.G. and K.M.; investigation, I.B., M.G., K.M. and M.Z.; writing-original draft preparation, M.Z.; writingreview and editing, I.B., M.G. and K.M. All authors have read and agreed to the published version of the manuscript.

Funding: This research was supported by Croatian Science Foundation under the project UIP-201904-8195 Cement stabilized base courses with waste rubber for sustainable pavements-RubSuPave.

Institutional Review Boards Statement: Not applicable.

Informed Consent Statement: Not applicable.

Conflicts of Interest: The authors declare no conflict of interest.

\section{References}

1. Zhu, X.; Bai, S.; Xue, G.; Yang, J.; Cai, Y.; Hu, W.; Jia, X.; Huang, B. Assessment of compaction quality of multi-layer pavement structure based on intelligent compaction technology. Constr. Build. Mater. 2018, 161, 316-329. [CrossRef]

2. Bezak, S.; Bezak, S.; Ereš, M. (Eds.) General Technical Conditions for Road Works; Institut građevinarstva Hrvatske: Zagreb, Croatia, 2001.

3. $\mathrm{Xu}, \mathrm{Q}$; Chang, G.K. Adaptive quality control and acceptance of pavement material density for intelligent road construction. Autom. Constr. 2016, 62, 78-88. [CrossRef]

4. Chen, L.; Qiao, L.; Li, Q. Study on dynamic compaction characteristics of gravelly soils with crushing effect. Soil Dyn. Earthq. Eng. 2019, 120, 158-169. [CrossRef]

5. Triantafyllidis, T.; Kimmig, I. A simplified model for vibro compaction of granular soils. Soil Dyn. Earthq. Eng. 2019, 122, 261-273. [CrossRef]

6. Chilukwa, N.N. Vibratory Hammer Compaction of Granular Materials; Stellenbosch University: Stellenbosch, South Africa, 2013.

7. Kodikara, J.; Islam, T.; Sounthararajah, A. Review of soil compaction: History and recent developments. Transp. Geotech. 2018, 17, 24-34. [CrossRef]

8. Fathi, A.; Tirado, C.; Rocha, S.; Mazari, M.; Nazarian, S. Assessing depth of influence of intelligent compaction rollers by integrating laboratory testing and field measurements. Transp. Geotech. 2021, 28, 100509. [CrossRef]

9. Pistrol, J.; Adam, D. Fundamentals of roller integrated compaction control for oscillatory rollers and comparison with conventional testing methods. Transp. Geotech. 2018, 17, 75-84. [CrossRef]

10. Pistrol, J.; Villwock, S.; Völkel, W.; Kopf, F.; Adam, D. Continuous Compaction Control (CCC) with Oscillating Rollers. Procedia Eng. 2016, 143, 514-521. [CrossRef]

11. Paulmichl, I.; Adam, C.; Adam, D. Analytical modeling of the stick-slip motion of an oscillation drum. Acta Mech. 2019, 230, 3103-3126. [CrossRef]

12. Hu, W.; Shu, X.; Huang, B.; Woods, M.E. An examination of compaction meter value for asphalt pavement compaction evaluation. Int. J. Pavement Eng. 2017, 19, 447-455. [CrossRef]

13. Hu, W.; Huang, B.; Shu, X.; Woods, M. Utilising intelligent compaction meter values to evaluate construction quality of asphalt pavement layers. Road Mater. Pavement Des. 2016, 18, 980-991. [CrossRef]

14. Hu, W.; Jia, X.; Zhu, X.; Gong, H.; Xue, G.; Huang, B. Investigating key factors of intelligent compaction for asphalt paving: A comparative case study. Constr. Build. Mater. 2019, 229, 116876. [CrossRef]

15. Ling, J.; Lin, S.; Qian, J.; Zhang, J.; Han, B.; Liu, M. Continuous Compaction Control Technology for Granite Residual Subgrade Compaction. J. Mater. Civ. Eng. 2018, 30, 04018316. [CrossRef]

16. Hu, W.; Shu, X.; Jia, X.; Huang, B. Geostatistical analysis of intelligent compaction measurements for asphalt pavement compaction. Autom. Constr. 2018, 89, 162-169. [CrossRef]

17. Leonard, L.; Ekwue, E.I.; Taylor, A.; Birch, R. Evaluation of a machine to determine maximum bulk density of soils using the vibratory method. Biosyst. Eng. 2019, 178, 109-117. [CrossRef]

18. Sengun, E.; Alam, B.; Shabani, R.; Yaman, I. The effects of compaction methods and mix parameters on the properties of roller compacted concrete mixtures. Constr. Build. Mater. 2019, 228, 116807. [CrossRef] 
19. Izquierdo, M.; Querol, X.; Vazquez, E. Procedural uncertainties of Proctor compaction tests applied on MSWI bottom ash. J. Hazard. Mater. 2011, 186, 1639-1644. [CrossRef]

20. Drnevich, V.; Evans, A.; Prochaska, A. A Study of Effective Soil Compaction Control of Granular Soils. Jt. Transp. Res. Program 2007. [CrossRef]

21. Hoff, I.; Bakløkk, L.J.; Aurstad, J. Influence of Laboratory Compaction Method on Unbound Granular Materials. In International Symposium on Pavements Unbound, 6th ed.; Dawson, A., Ed.; CRC Press: Nottingham, England, 2004.

22. McLachlan, R.; Bagshaw, S. Standardisation of Laboratory Compaction Energies; NZ Transport Agency: Wellington, New Zeland, 2017.

23. Wu, P.; Houben, L.J.M. Investigation of the Effects of Different Laboratory Compacting Methods on the Properties of Cement Stabilized Materials. In Proceedings of the Ninth International Conference on the Bearing Capacity of Roads, Railways and Airfields, Trondheim, Norway, 25-27 June 2013; Hoff, I., Mork, H., Garba Saba, R., Eds.; CRC Press: Boca Raton, FL, USA, 2018; Volume 2.

24. Scott, B.T.; Jaksa, M.B.; Mitchell, P. Influence of towing speed on effectiveness of rolling dynamic compaction. J. Rock Mech. Geotech. Eng. 2020, 12, 126-134. [CrossRef]

25. Farhan, A.H.; Dawson, A.R.; Thom, N.H. Characterization of rubberized cement bound aggregate mixtures using indirect tensile testing and fractal analysis. Constr. Build. Mater. 2016, 105, 94-102. [CrossRef]

26. Farhan, A.H.; Dawson, A.R.; Thom, N.H. Effect of cementation level on performance of rubberized cement-stabilized aggregate mixtures. Mater. Des. 2016, 97, 98-107. [CrossRef]

27. Huang, W.; Huang, X.; Xing, Q.; Zhou, Z. Strength reduction factor of crumb rubber as fine aggregate replacement in concrete. J. Build. Eng. 2020, 32, 101346. [CrossRef]

28. Habib, A.; Yildirim, U.; Eren, O. Mechanical and dynamic properties of high strength concrete with well graded coarse and fine tire rubber. Constr. Build. Mater. 2020, 246, 118502. [CrossRef]

29. Gou, Y.; Zhang, L.; Liu, C.; Zhang, H.; Wei, C.; Cai, X.; Yang, H.; Guan, Q.; Zhai, S.; Liu, L. Investigation of freeze-thaw mechanism for crumb rubber concrete by the online strain sensor. Measurement 2021, 174, 109080. [CrossRef]

30. European Commitee for Standardization. HRN EN 933-1: 2012 Test for Geometrical Properties of Aggregates-Part 1: Determination of Particle size Distribution—Sievin Method; CEN: Brussels, Belgium, 2012.

31. European Commitee for Standardization. HRN EN 13285:2018 Unbound Mixtures—Specifications; CEN: Brussels, Belgium, 2018.

32. European Commitee for Standardization. HRN EN 14227-1:2013 Hydraulically bound mixtures—Specifications—Part 1: Cement Bound Granular Mixtures; CEN: Brussels, Belgium, 2013.

33. European Commitee for Standardization. HRN EN 1097-6:2013 Test for Mechanical and Physical Properties of Aggregates-Part 6: Determination of Particle Density and Water Absorption; CEN: Brussels, Belgium, 2013.

34. European Commitee for Standardization. HRN EN 196-6:2018 Methods of Testing Cement_Part 6: Determination of Fineness; CEN: Brussels, Belgium, 2018.

35. Barišić, I.; Dimter, S.; Rukavina, T. Characterization of cement stabilized pavement layers with ultrasound testing. Teh. Vjesn. Tech. Gaz. 2016, 23, 447-453. [CrossRef]

36. European Commitee for Standardization. HRN EN 13286-51:2004 Unbound and Hydraulically Bound Mixtures—Part 51: Methods for the Manufacture of Test Specimens of Hydraulically Bound Mixtures Using Vibrating Hammer Compaction; CEN: Brussels, Belgium, 2004.

37. European Commitee for Standardization. HRN EN 13286-2:2010 Unbound and Hydraulically Bound Mixtures-Part 2: Test Method for Laboratory Dry Density and Water Content_Proctor Compaction; CEN: Brussels, Belgium, 2010.

38. European Commitee for Standardization. HRN EN 13286-4:2003 Unbound and Hydraulically Bound Mixtures-Part 4: Test Methods for Laboratory Reference Density and Water Content_Vibrating Hammer; CEN: Brussels, Belgium, 2003.

39. European Commitee for Standardization. HRN EN 13286-47:2012 Unbound and Hydraullically Bound Mixtures—Part 47: Test Method for the Determination of California Bearing Ratio, Immediate Bearing Index and Linear Swelling; CEN: Brussels, Belgium, 2012.

40. European Commitee for Standardization. HRN EN 13286-41:2003 Unbound and Hydraulically Bound Mixtures-Pari 41: Test Method for the Determination of the Compressive Strenght of Hydraulically Bound Mixtures; CEN: Brussels, Belgium, 2003.

41. European Commitee for Standardization. EN 13286-50 Unbound and hydraulicylly Bound Mixtures—Part 50: Method for the Manufacture of Test Specimens of Hydraulically Bound Mixtures Using Proctor Equipment or Vibrating Table Compaction; CEN: Brussels, Belgium, 2004.

42. Ovad, E.; Barišić, I.; Zagvozda, M. Comparison of Croatian and European standards for Determining the Frost Suspectibility of Hydraulically Bound Mixtures. e-GFOS 2014, 5, 41-48. [CrossRef]

43. Farhan, A.H.; Dawson, A.R.; Thom, N.H.; Adam, S.; Smith, M.J. Flexural characteristics of rubberized cement-stabilized crushed aggregate for pavement structure. Mater. Des. 2015, 88, 897-905. [CrossRef]

44. Sun, X.; Wu, S.; Yang, J.; Yang, R. Mechanical properties and crack resistance of crumb rubber modified cement-stabilized macadam. Constr. Build. Mater. 2020, 259, 119708. [CrossRef] 